Exp. Anim. 67(2), 193-200, 2018

\title{
-Original-
}

\section{Sevoflurane preconditioning ameliorates lipopolysaccharide-induced cognitive impairment in mice}

\author{
Maiko SATOMOTO ${ }^{1,2) *}$, Zhongliang $\mathrm{SUN}^{1) *}$, Yushi U. ADACHI ${ }^{1)}$, \\ Hiroyuki KINOSHITA ${ }^{3)}$, and Koshi MAKITA ${ }^{1)}$ \\ 1)Department of Anesthesiology, Graduate School of Medical and Dental Sciences, Tokyo Medical and Dental \\ University, 1-5-45 Yushima, Bunkyo-ku, Tokyo 113-8519, Japan \\ 2) Present address: Department of Anesthesiology, Graduate School of Medicine, Nagoya University, 65 Tsurumai, \\ Showa-ku, Nagoya-shi, Aichi 466-8550, Japan \\ ${ }^{3)}$ Department of Anesthesiology, Aichi Medical University School of Medicine, 1-1 Yazako Karimata, Nagakute-shi, \\ Aichi 480-1195, Japan
}

\begin{abstract}
Systemic inflammation induces brain neuronal inflammation, in turn causing acute cognitive disorders. Furthermore, neuronal inflammation is one cause of postoperative cognitive disorder (POCD) and delirium. However, no sufficiently established pharmacological treatment is available for neurocognitive inflammation. This study evaluated the possible neuroprotective effects of preconditioning with sevoflurane anesthesia on cognition and neuroinflammatory changes in an animal model of lipopolysaccharide (LPS)-induced systemic inflammation. Adult mice were randomly divided into (1) control, (2) $2 \%$ sevoflurane preconditioning for $1 \mathrm{~h}$, (3) intraperitoneal $5 \mathrm{mg} / \mathrm{kg}$ LPS injection, and (4) $2 \%$ sevoflurane preconditioning for $1 \mathrm{~h}+$ LPS injection groups. At $24 \mathrm{~h}$ after $5 \mathrm{mg} / \mathrm{kg}$ LPS injection, microglial activation based on ionized calcium-binding adapter molecule 1 (Iba-1) expression in the hippocampus was determined using immunostaining and immunoblotting. IL-1 $\beta$ and IL-6 immunoblotting were used as inflammation markers, and $\beta$-site of amyloid precursor protein cleaving enzyme 1 (BACE1) immunoblotting was performed to evaluate amyloid $\beta$-protein (A $\beta$ ) accumulation. Long-term cognitive impairment was evaluated using fear conditioning tests. Intraperitoneal LPS increased levels of Iba-1 (150\%), inflammation markers (160\%), and $A \beta$ accumulation (350\%), and sevoflurane preconditioning suppressed these increases. Systemic LPS caused learning deficits. Sevoflurane also maintained long-term memory in mice receiving LPS injection. Sevoflurane preconditioning prevented long-term memory impairment in the mouse model administered systemic LPS by decreasing excessive microglial activation, inflammation, and $A \beta$ accumulation. This study supports the hypothesis that sevoflurane preconditioning might also be beneficial for neuronal inflammation. Sevoflurane might be beneficial for reducing delirium and POCD.
\end{abstract}

Key words: cognitive dysfunction, neuronal inflammation, sevoflurane

(Received 6 September 2017 / Accepted 8 November 2017 / Published online in J-STAGE 29 November 2017)

*Theses authors contributed equally to this work.

Address corresponding: M. Satomoto, Department of Anaesthesiology, Graduate School of Medical and Dental Sciences, Tokyo Medical and Dental University, 1-5-45 Yushima, Bunkyo-ku, Tokyo 113-8519, Japan

(c) $\odot$ This is an open-access article distributed under the terms of the Creative Commons Attribution Non-Commercial No Derivatives cc) ${ }_{\mathrm{BY}} \mathrm{NC}_{\mathrm{ND}}(b y-n c-n d)$ License <http://creativecommons.org/licenses/by-nc-nd/4.0/>

(C)2018 Japanese Association for Laboratory Animal Science 


\section{Introduction}

Systemic inflammation induces brain neuronal inflammation [23]. Neuronal inflammation can cause postoperative cognitive disorder (POCD) and delirium [30], which have significant morbidity and mortality [23]. There is no cure for neuronal inflammation, so clinicians focus on treating the systemic inflammation.

Sevoflurane is a widely used inhalational anesthetic in clinical practice. Preclinical data suggest that sevoflurane preconditioning can induce ischemic tolerance neuroprotection $[18,36,38]$. The mechanisms of sevoflurane preconditioning might be associated with the inhibition of microglial activation [24], which is a crucial factor in brain inflammation [5]. Sevoflurane prevents lipopolysaccharide (LPS)-induced barrier dysfunction in human lung microvascular endothelial cells [12] and LPS-induced myocardial inflammation [19]. Although sevoflurane anesthesia may have a neuroprotective effect, few studies have shown that sevoflurane is beneficial for neuronal inflammation.

In the current study, we investigated the possible neuroprotective effects of clinical concentrations of sevoflurane on brain neuronal inflammation. We attempted to conduct the experiments in a more clinical manner, so we opted for intraperitoneal LPS injection rather than intracranial LPS injection. We hypothesized that sevoflurane would be beneficial for reducing the incidence of delirium and POCD because it has protective effects in neuronal inflammation. In this study, we investigated whether sevoflurane protects against LPS-induced cognitive dysfunction and investigated the mechanism of the protective effects of sevoflurane on LPS-induced cognitive dysfunction.

\section{Materials and Methods}

\section{Ethics approval}

The Animal Care and Use Committee of Tokyo Medical and Dental University approved the study protocol (0160393A and 0170003A).

\section{Experimental mice}

Six-month-old male C57BL/6NCr strain mice (26-33 g) were used in this study (SLC Japan, Shizuoka, Japan). The mice were housed under a 12-h light-dark cycle (lights on from 08:00 to 20:00), and room temperature was maintained at $21 \pm 1^{\circ} \mathrm{C}$. The study used 80 mice.

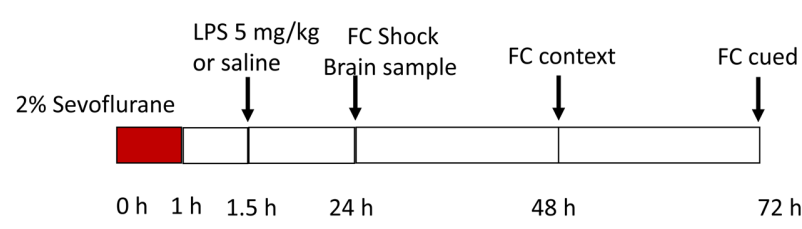

Fig. 1. Timeline of the experimental procedure. FC, fear conditioning. Mice were administered $2 \%$ sevoflurane or carrier gas only for $1 \mathrm{~h}$ before receiving a $5 \mathrm{mg} / \mathrm{kg}$ lipopolysaccharide (LPS) or saline intraperitoneal injection. Twenty-four $\mathrm{h}$ after LPS injection, brain samples were taken for Western blotting. A fear conditioning test was performed on days 2,3 , and 4 .

The animals were randomly divided into four groups: (1) $60 \%$ oxygen for $1 \mathrm{~h}+$ saline (Saline group, control mice), (2) $2 \%$ sevoflurane (carrier gas: $60 \%$ oxygen) preconditioning for $1 \mathrm{~h}+$ saline (SEVO group), (3) $60 \%$ oxygen for $1 \mathrm{~h}+$ LPS injection (LPS group), and (4) $2 \%$ sevoflurane (carrier gas: $60 \%$ oxygen) preconditioning for $1 \mathrm{~h}+$ LPS injection (SEVO + LPS group). Sevoflurane preconditioning was performed $30 \mathrm{~min}$ before intraperitoneal LPS injection (Fig. 1). All mice had $a d$ libitum access to water and food. This study employed only male mice to avoid potential variability caused by the estrous cycle [27].

\section{Experimental protocol}

LPS (Lipopolysaccharides from Escherichia coli O55:B5, Sigma-Aldrich, St. Louis, MO, USA) was dissolved in saline at a concentration of $5 \mathrm{mg} / \mathrm{kg}$. Control animals were injected with the same volume of saline $(0.1 \mathrm{ml}$, vehicle). All mice inhaled $2 \%$ sevoflurane (in $60 \%$ oxygen $)$ for $1 \mathrm{~h}$ in a humidified chamber $(180 \times 180$ $\times 200 \mathrm{~mm}$ ) at $39 \pm 1{ }^{\circ} \mathrm{C}$ with a total gas flow of $2 \mathrm{l} / \mathrm{min}$.

\section{Fear conditioning test}

Behavioral studies were performed as described previously $[32,34]$. Briefly, a conditioning (acquisition) trial was performed $24 \mathrm{~h}$ after $5 \mathrm{mg} / \mathrm{kg}$ LPS injection. The test comprised three conditioned-unconditioned stimulus pairings separated by 1-min intervals. Each pairing was as follows: unconditioned stimulus, $0.5 \mathrm{~mA}$ foot shock for $1 \mathrm{~s}$; conditioned stimulus, $60 \mathrm{~dB}$ white noise for $20 \mathrm{~s}$. The unconditioned stimulus was delivered during the last seconds of the conditioned stimulus. A contextual test was performed $24 \mathrm{~h}$ after conditioning. The contextual test was performed in the conditioning chamber for $5 \mathrm{~min}$ in the absence of white noise. A cued test was performed by presenting a cue $(60 \mathrm{~dB}$ white noise, 
3-min duration) in an alternate context with distinct visual and tactile cues $48 \mathrm{~h}$ after conditioning. The freezing response rate was recorded automatically and used to measure fear memory. The freezing percentage during each test was compared between groups.

\section{Western blot analysis}

We used intraperitoneal injection of $5 \mathrm{mg} / \mathrm{kg}$ LPS for the biochemical experiments. At $24 \mathrm{~h}$ after the LPS injection, the hippocampus was isolated and quickly frozen at $-80^{\circ} \mathrm{C}$. Western blot analysis was performed, as described previously [34]. The frozen hippocampus was homogenized in $150 \mu 1$ homogenization buffer containing $20 \mathrm{mM}$ Tris- $\mathrm{HCl}(\mathrm{pH}$ 7.5), $1 \mathrm{mM}$ EDTA, $1 \mathrm{mM}$ $\mathrm{Na}_{4} \mathrm{P}_{2} \mathrm{O}_{7}$, and a protease inhibitor cocktail. The lysate was centrifuged at $14,000 \mathrm{rpm}$ for $15 \mathrm{~min}$ at $4^{\circ} \mathrm{C}$. The supernatant was removed and stored at $-80^{\circ} \mathrm{C}$ until use. The amount of protein in each sample was measured using a protein assay kit (Pierce BCA Protein Assay Kit, BCA; Pierce, Rockford, IL, USA). Proteins were separated by SDS-PAGE and transferred to PVDF membranes (Trans-Blot ${ }^{\circledR}$ Turbo $^{\text {TM }}$ Mini PVDF Transfer Packs, Bio-Rad, Hercules, CA, USA). The primary antibodies included anti-IL-6 (ab6672, rabbit polyclonal, Abcam, Cambridge, MA, USA), anti-IL-1 $\beta$ (ab9722, rabbit polyclonal, Abcam), anti- $\beta$-site amyloid precursor protein-cleaving enzyme (BACE) 1 (ab2077, rabbit polyclonal, Abcam), anti-Iba-1 (for Western blotting, rabbit polyclonal, Wako Pure Chemical Industries), and anti$\beta$-actin (AC-15, mouse monoclonal, Sigma-Aldrich, St. Louis, MO, USA). Secondary antibodies included HRPlinked anti-rabbit IgG (ab98493, donkey polyclonal, Abcam) and HRP-linked anti-mouse IgG (NA9310, sheep, GE Healthcare, Little Chalfont, England). $\beta$-Actin antibody was used as the loading control. The protein bands were visualized using a chemiluminescence detection system (SuperSignal West Pico, Pierce).

\section{Histopathological evaluation}

We injected (intraperitoneal) $5 \mathrm{mg} / \mathrm{kg}$ LPS for the immunohistochemistry study to support the Western blot analyses. Immunohistochemical staining was performed as described previously [34]. Briefly, the mice were perfused under intraperitoneal pentobarbital anesthesia 24 $\mathrm{h}$ after the $5 \mathrm{mg} / \mathrm{kg}$ LPS injection. For immunohistochemistry, $50-\mu \mathrm{m}$-thick floating coronal vibratome sections (bregma $-2.06 \mathrm{~mm}$ ) were obtained. Ionized calcium-binding adapter molecule 1 (Iba-1) staining was performed to observe the microglial response. An antiIba-1 antibody was used (for immunocytochemistry; rabbit polyclonal, Wako Pure Chemical Industries, Osaka, Japan). The sections were then incubated with horseradish peroxidase (HRP)-linked anti-rabbit IgG (ab98493, donkey polyclonal, Abcam). The Iba-1 signal was visualized using a DAB-nickel substrate $(0.05 \%$ $\mathrm{DAB}, 0.05 \% \mathrm{NiSO}_{4}, 0.015 \% \mathrm{H}_{2} \mathrm{O}_{2}, 0.05 \% 1 \mathrm{M}$ Tris-HCl; pH 6.7). Then, the sections were mounted on slides using brushes and dried overnight. Finally, the slides were covered with cover glasses.

\section{Statistical analysis}

Statistical analysis was performed IBM SPSS Statistics Ver. 24.0 (IBM, Armonk, NY, USA). The data were expressed as the means \pm SEM. The levels of protein expression detected by western blot analysis were expressed as a percentage of the control (saline group) value. Data were analyzed using analysis of variance (two-way factorial ANOVA) with a Bonferroni post hoc test. Differences were considered to be statistically significant when $P<0.05$.

\section{Sample size estimation}

A sample size of six in each group for the Western blot analysis and 10 in each group for behavior was sufficient to detect a difference in the treatment effect using analysis of variance (ANOVA) with $80 \%$ power and a 0.05 significance level (PASS 11.0, NCSS, Kaysville, UT, USA).

\section{Results}

\section{Evaluation of long-term memory}

The $5 \mathrm{mg} / \mathrm{kg}$ LPS injection significantly reduced the freezing response in both the contextual (Fig. 2A) and cued (Fig. 2B) fear conditioning tests. Sevoflurane preconditioning abrogated this decline in long-term memory function (Figs. 2A and B). These results indicated that sevoflurane preconditioning suppresses the impairment of long-term memory caused by intraperitoneal LPS injection.

\section{Evaluation of microglial activation}

Intraperitoneal injection of $5 \mathrm{mg} / \mathrm{kg}$ LPS injection increased microglial activation in the hippocampus, as shown by Iba-1 staining. Sevoflurane preconditioning abolished this effect of LPS injection (Figs. 3A-D). The 
A

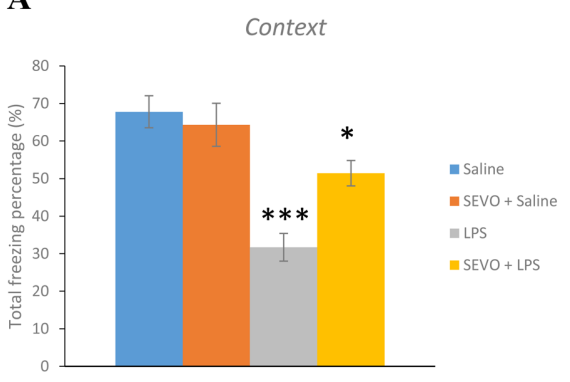

B

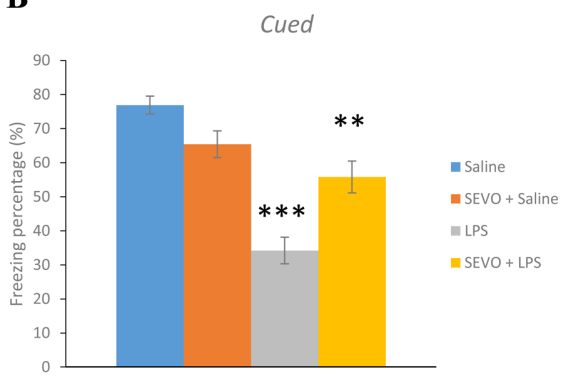

Fig. 2. Long-term memory evaluation using fear conditioning tests in mice with or without $5 \mathrm{mg} /$ $\mathrm{kg}$ lipopolysaccharide (LPS) systemic injection. (A) The freezing response in the contextual test $(* * * P<0.001$ for saline vs. LPS; $* P<0.05$ for LPS vs. sevoflurane [SEVO] + LPS; $\mathrm{n}=10$ mice each). (B) The freezing response in the cued test $(* * * P<0.001$ for saline vs. LPS; ${ }^{*} P<0.01$ for LPS vs. SEVO + LPS; $\mathrm{n}=10$ mice each).
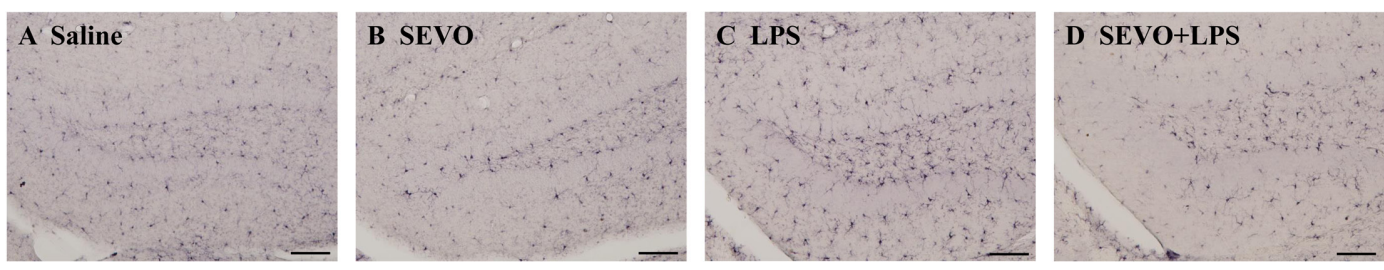

$\mathbf{E}$

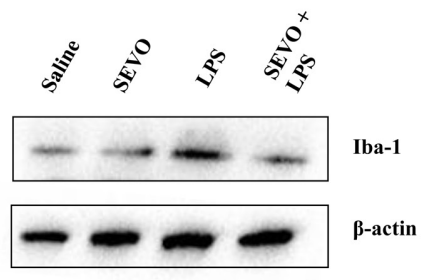

F

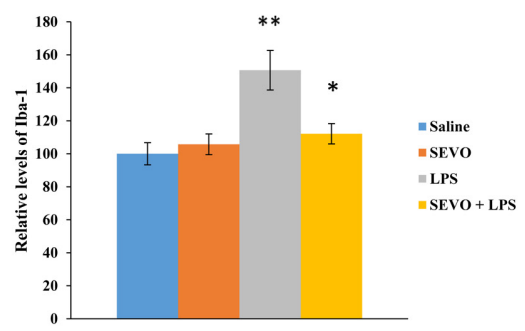

Fig. 3. Microglial activation in the hippocampus indicated by ionized calcium-binding adapter molecule 1 (Iba-1) staining (scale bar=100 $\mu \mathrm{m}$ ). Black dots indicate Iba-1-positive cells in the (A) saline, (B) sevoflurane (SEVO), (C) lipopolysaccharide (LPS), and (D) SEVO + LPS groups ( $\mathrm{n}=4$ mice each). (E) Cumulative data showing the Iba-1 levels in the hippocampus in the 24-h period after $5 \mathrm{mg} / \mathrm{kg}$ LPS injection in mice $(* * P<0.01$ for Saline vs. LPS; ${ }^{*} P<0.05$ for LPS vs. SEVO + LPS; $\mathrm{n}=6$ mice each).

hippocampal levels of the microglial activation marker Iba-1 were also elevated after LPS injection, and sevoflurane also inhibited this increase (Figs. 3E and F).

\section{Brain inflammation}

The $5 \mathrm{mg} / \mathrm{kg}$ LPS injection increased the levels of IL-6 and IL- $1 \beta$ in the hippocampus, and sevoflurane preconditioning suppressed this increase (Figs. 4A and B).

\section{A $\beta$ accumulation}

Injection of $5 \mathrm{mg} / \mathrm{kg}$ LPS increased the levels of $\beta$-site amyloid precursor protein-cleaving enzyme (BACE) 1 , which resulted in $A \beta$ accumulation, and sevoflurane preconditioning suppressed this increase (Fig. 5).

\section{Discussion}

Consistent with previous studies [3, 7, 8, 23], intraperitoneal injection of $5 \mathrm{mg} / \mathrm{kg}$ LPS produced an approximately $40 \%$ reduction in the freezing response in the contextual and cued fear conditioning tests, indicating that LPS impaired both hippocampus-dependent and hippocampus-independent memory [32, 34]. In this study, intraperitoneal injection of $5 \mathrm{mg} / \mathrm{kg}$ LPS increased 
A

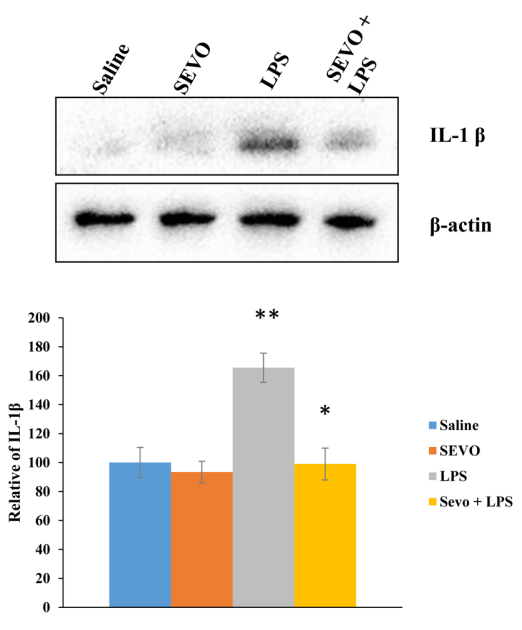

B
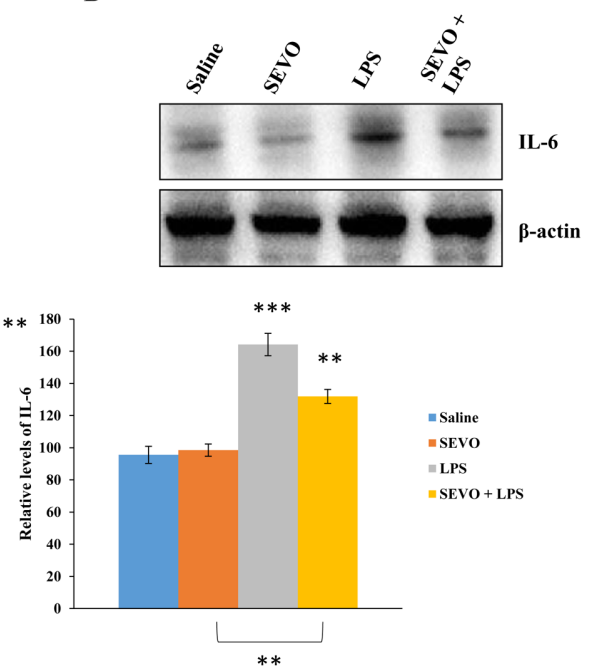

Fig. 4. Expression of inflammation markers in the hippocampus. (A) IL- $1 \beta$ levels $24 \mathrm{~h}$ after $5 \mathrm{mg} /$ $\mathrm{kg}$ lipopolysaccharide (LPS) injection $\left(* * P<0.01\right.$ for saline vs. LPS; ${ }^{*} P<0.05$ for LPS vs. sevoflurane [SEVO] + LPS; $\mathrm{n}=6$ mice each). (B) IL-6 levels $24 \mathrm{~h}$ after $5 \mathrm{mg} / \mathrm{kg}$ LPS injection (*** $P<0.001$ for Saline vs. LPS; $* * P<0.01$ for LPS vs. SEVO + LPS; $\mathrm{n}=6$ mice each).
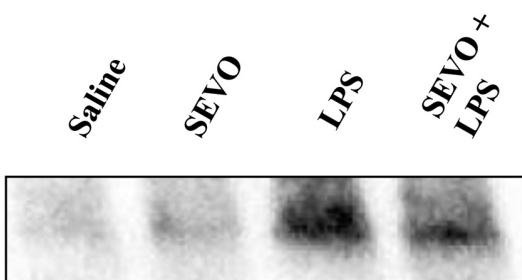

BACE1

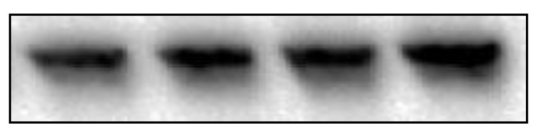

$\beta$-actin

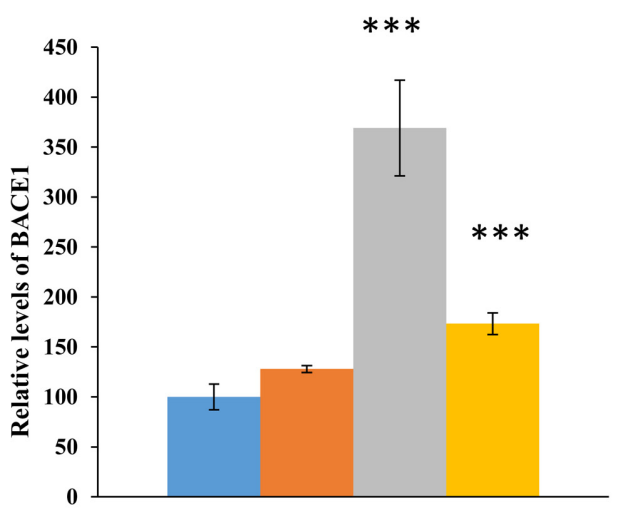

- Saline

-SEVO

$=$ LPS

SEVO + LPS

Fig. 5. The $\beta$-site amyloid precursor protein-cleaving enzyme (BACE) 1 levels in the hippocampus $24 \mathrm{~h}$ after $5 \mathrm{mg} / \mathrm{kg}$ lipopolysaccharide (LPS) injection $(* * * P<0.001$ for saline vs. LPS and for LPS vs. sevoflurane [SEVO] + LPS; $n=6$ mice each). inflammation and $\mathrm{A} \beta$ accumulation along with microglial activation in the brain. Importantly, sevoflurane preconditioning prevented intracerebral inflammation, excessive microglial activation, and $\mathrm{A} \beta$ accumulation and further prevented the reduction in long-term memory function induced by intraperitoneal LPS injection. These results suggest that sevoflurane preconditioning protected against the long-term memory impairment induced by systematic LPS injection in an animal model of systemic inflammation by alleviating neuronal inflammation.

Accumulated evidence has demonstrated that exacerbated neuronal inflammation is the central step in the development of long-term cognitive impairment $[7,35]$. Systemic LPS administration increased the levels of IL-6 and IL-1 $\beta$, two major proinflammatory mediators released by activated microglia and astrocytes. Due to the suppression of proinflammatory mediators, coadministration of minocycline improved the LPS-induced cognitive impairment [11]. This study demonstrated that sevoflurane preconditioning significantly suppressed the LPS-induced IL- 6 and IL- $1 \beta$ production, as well as microglial activation in the mouse hippocampus.

Sevoflurane suppressed excessive microglial activation in this study, which means that it inhibited proinflammatory mediators released by activated microglia and astrocytes. Microglial over-activation is the crucial 
factor involved in brain inflammation [11, 25], so we showed that sevoflurane improved long-term memory impairment by suppressing brain inflammation induced by intraperitoneal injection of $5 \mathrm{mg} / \mathrm{kg}$ LPS.

BACE1 levels are reported to correlate with the degree of cognitive impairment [3, 7, 37]. The BACE1 level is used in research on Alzheimer's disease [2,33]. Choi et al. [3] reported that obovatol suppressed the LPS-induced BACE1 elevation and improved cognitive impairment. Our results indicated that sevoflurane prevented the learning disability induced by LPS injection by suppressing BACE1.

Anesthesia contributes to the development of postoperative infections and the spread of malignant disease due to the patient's poor health status [31]. Deep anesthesia is independently associated with postoperative mortality [17]. In contrast, Hermann et al. [9] reported that administration of the volatile anesthetic sevoflurane significantly improved mortality in a cecal ligation and puncture model. They concluded that volatile anesthetics have beneficial immunomodulatory effects on complex inflammation-mediated conditions in both nonhuman animals [4, 10, 20-22, 29] and humans [1, 15, 16]. The results of this study were consistent with those findings.

We administered $2 \%$ sevoflurane for $1 \mathrm{~h}$ before the LPS injection based on Li's protocol [24]. In adult mice, the minimum alveolar concentration was found to be $2.5-3.2 \%[13,28]$. The results of the present study showed that in healthy adult mice, $2 \%$ sevoflurane did not cause respiratory or circulatory depression. Sevoflurane preconditioning was performed $30 \mathrm{~min}$ before intraperitoneal LPS injection as previously described [24]. A 30-min interval is sufficient for full recovery from sevoflurane anesthesia. In addition, the SEVO groups exhibited no hemodynamic changes compared with the control groups.

In the intensive care unit, sevoflurane is better than propofol [14] and midazolam [6] for sedation in acute respiratory distress syndrome in terms of the inflammatory response and oxygenation. Suppression of the excessive immune response to which sevoflurane contributes might be beneficial for patients with both systemic and neuronal inflammatory. The suppression of neuronal inflammation might be beneficial for postoperative delirium and POCD.

Our study clearly shows significant beneficial effects of sevoflurane preconditioning via the inhibition of microglial activation. However, this requires validation in other animal models. Different anesthesia protocols may give different outcomes. For example, there are reports that exposure to sevoflurane causes an inflammatory reaction and long-term memory impairment in aged and neonatal rodents $[26,32,34]$.

We did not measure peripheral cytokine levels in this experiment. It would have been better to measure both intracranial cytokine levels and peripheral cytokine levels at the same time.

\section{Conclusions}

We demonstrated that sevoflurane preconditioning prevented long-term memory impairment in mice following systemic LPS administration by decreasing excessive microglial activation, inflammation, and $A \beta$ accumulation. This study supports the hypothesis that sevoflurane preconditioning might be beneficial for neuronal inflammatory patients. Sevoflurane might also be beneficial for reducing delirium and POCD.

\section{Conflicts of Interest}

The authors declare that they have no conflicts of interest.

\section{Acknowledgments}

We thank Ailing Zhang and Chenmin Li (Department of Anesthesiology, Graduate School of Medicine, Nagoya University, Nagoya, Japan) for their excellent technical help with this study. This work was supported by the program for women researchers of the Tokyo Medical and Dental University in 2016 and funded by the Initiative for Realizing Diversity in the Research Environment of the Ministry of Education, Culture, Sports, Sciences and Technology, Japan, and Japan Society the Promotion of Science (Tokyo, Japan) Grants Number 16K10928.

\section{References}

1. Beck-Schimmer, B., Breitenstein, S., Urech, S., De Conno, E., Wittlinger, M., Puhan, M., Jochum, W., Spahn, D.R., Graf, R., and Clavien, P.A. 2008. A randomized controlled trial on pharmacological preconditioning in liver surgery using a volatile anesthetic. Ann. Surg. 248: 909-918. [Medline] [CrossRef]

2. Carret-Rebillat, A.S., Pace, C., Gourmaud, S., Ravasi, L., Montagne-Stora, S., Longueville, S., Tible, M., Sudol, E., 
Chang, R.C., Paquet, C., Mouton-Liger, F., and Hugon, J. 2015. Neuroinflammation and $A \beta$ accumulation linked to systemic inflammation are decreased by genetic PKR downregulation. Sci. Rep. 5: 8489. [Medline] [CrossRef]

3. Choi, D.Y., Lee, J.W., Lin, G., Lee, Y.K., Lee, Y.H., Choi, I.S., Han, S.B., Jung, J.K., Kim, Y.H., Kim, K.H., Oh, K.W., Hong, J.T., and Lee, M.S. 2012. Obovatol attenuates LPSinduced memory impairments in mice via inhibition of NFкB signaling pathway. Neurochem. Int. 60: 68-77. [Medline] [CrossRef]

4. Cope, D.K., Impastato, W.K., Cohen, M.V., and Downey, J.M. 1997. Volatile anesthetics protect the ischemic rabbit myocardium from infarction. Anesthesiology 86: 699-709. [Medline] [CrossRef]

5. Deng, Y.Y., Fang, M., Zhu, G.F., Zhou, Y., and Zeng, H.K. 2013. Role of microglia in the pathogenesis of sepsis-associated encephalopathy. CNS Neurol. Disord. Drug Targets 12: 720-725. [Medline] [CrossRef]

6. Ferrando, C., Aguilar, G., Piqueras, L., Soro, M., Moreno, J., and Belda, F.J. 2013. Sevoflurane, but not propofol, reduces the lung inflammatory response and improves oxygenation in an acute respiratory distress syndrome model: a randomised laboratory study. Eur. J. Anaesthesiol. 30: 455-463. [Medline] [CrossRef]

7. Frühauf, P.K., Ineu, R.P., Tomazi, L., Duarte, T., Mello, C.F., and Rubin, M.A. 2015. Spermine reverses lipopolysaccharide-induced memory deficit in mice. J. Neuroinflammation 12: 3. [Medline] [CrossRef]

8. Gao, R., Tang, Y.H., Tong, J.H., Yang, J.J., Ji, M.H., and Zhu, S.H. 2015. Systemic Lipopolysaccharide Administration-Induced Cognitive Impairments are Reversed by Erythropoietin Treatment in Mice. Inflammation 38: 1949-1958. [Medline] [CrossRef]

9. Herrmann, I.K., Castellon, M., Schwartz, D.E., Hasler, M., Urner, M., Hu, G., Minshall, R.D., and Beck-Schimmer, B. 2013. Volatile anesthetics improve survival after cecal ligation and puncture. Anesthesiology 119: 901-906. [Medline] [CrossRef]

10. Hofstetter, C., Boost, K.A., Flondor, M., Basagan-Mogol, E., Betz, C., Homann, M., Muhl, H., Pfeilschifter, J., and Zwissler, B. 2007. Anti-inflammatory effects of sevoflurane and mild hypothermia in endotoxemic rats. Acta Anaesthesiol. Scand. 51: 893-899. [Medline] [CrossRef]

11. Hou, Y., Xie, G., Liu, X., Li, G., Jia, C., Xu, J., and Wang, B. 2016. Minocycline protects against lipopolysaccharideinduced cognitive impairment in mice. Psychopharmacology (Berl.) 233: 905-916. [Medline] [CrossRef]

12. Huang, Y., Tan, Q., Chen, R., Cao, B., and Li, W. 2015. Sevoflurane prevents lipopolysaccharide-induced barrier dysfunction in human lung microvascular endothelial cells: Rho-mediated alterations of VE-cadherin. Biochem. Biophys. Res. Commun. 468: 119-124. [Medline] [CrossRef]

13. Ichinose, F., Mi, W.D., Miyazaki, M., Onouchi, T., Goto, T., and Morita, S. 1998. Lack of correlation between the reduction of sevoflurane MAC and the cerebellar cyclic GMP concentrations in mice treated with 7-nitroindazole. Anesthesiology 89: 143-148. [Medline] [CrossRef]

14. Jabaudon, M., Boucher, P., Imhoff, E., Chabanne, R., Faure,
J.S., Roszyk, L., Thibault, S., Blondonnet, R., Clairefond, G., Guérin, R., Perbet, S., Cayot, S., Godet, T., Pereira, B., Sapin, V., Bazin, J.E., Futier, E., and Constantin, J.M. 2017. Sevoflurane for Sedation in Acute Respiratory Distress Syndrome. A Randomized Controlled Pilot Study. Am. J. Respir. Crit. Care Med. 195: 792-800. [Medline] [CrossRef]

15. Julier, K., da Silva, R., Garcia, C., Bestmann, L., Frascarolo, P., Zollinger, A., Chassot, P.G., Schmid, E.R., Turina, M.I., von Segesser, L.K., Pasch, T., Spahn, D.R., and Zaugg, M. 2003. Preconditioning by sevoflurane decreases biochemical markers for myocardial and renal dysfunction in coronary artery bypass graft surgery: a double-blinded, placebo-controlled, multicenter study. Anesthesiology 98: 1315-1327. [Medline] [CrossRef]

16. Kato, R. and Foëx, P. 2002. Myocardial protection by anesthetic agents against ischemia-reperfusion injury: an update for anesthesiologists. Can. J. Anaesth. 49: 777-791. [Medline] [CrossRef]

17. Kertai, M.D., Pal, N., Palanca, B.J., Lin, N., Searleman, S.A., Zhang, L., Burnside, B.A., Finkel, K.J., Avidan, M.S., B-Unaware Study Group 2010. Association of perioperative risk factors and cumulative duration of low bispectral index with intermediate-term mortality after cardiac surgery in the B-Unaware Trial. Anesthesiology 112: 1116-1127. [Medline] [CrossRef]

18. Kitano, H., Kirsch, J.R., Hurn, P.D., and Murphy, S.J. 2007. Inhalational anesthetics as neuroprotectants or chemical preconditioning agents in ischemic brain. J. Cereb. Blood Flow Metab. 27: 1108-1128. [Medline] [CrossRef]

19. Lai, J., Zhang, L., Wang, H., Lin, P., and Chen, W. 2014. [Effects of sevoflurane preconditioning on cardiomyocyte apoptosis and myocardial inflammation in rats with sepsis]. Nan Fang Yi Ke Da Xue Xue Bao 34: 1680-1683. (in Chinese) [Medline]

20. Lee, H.T., Emala, C.W., Joo, J.D., and Kim, M. 2007. Isoflurane improves survival and protects against renal and hepatic injury in murine septic peritonitis. Shock 27: 373-379. [Medline] [CrossRef]

21. Lee, H.T., Kim, M., Kim, M., Kim, N., Billings, F.T. 4th., D'Agati, V.D., and Emala, C.W. Sr. 2007. Isoflurane protects against renal ischemia and reperfusion injury and modulates leukocyte infiltration in mice. Am. J. Physiol. Renal Physiol. 293: F713-F722. [Medline] [CrossRef]

22. Lee, J.J., Li, L., Jung, H.H., and Zuo, Z. 2008. Postconditioning with isoflurane reduced ischemia-induced brain injury in rats. Anesthesiology 108: 1055-1062. [Medline] [CrossRef]

23. Lee, J.W., Lee, Y.K., Yuk, D.Y., Choi, D.Y., Ban, S.B., Oh, K.W., and Hong, J.T. 2008. Neuro-inflammation induced by lipopolysaccharide causes cognitive impairment through enhancement of beta-amyloid generation. J. Neuroinflammation 5: 37. [Medline] [CrossRef]

24. Li, X., Luo, P., Wang, F., Yang, Q., Li, Y., Zhao, M., Wang, S., Wang, Q., and Xiong, L. 2014. Inhibition of N-myc downstream-regulated gene-2 is involved in an astrocyte-specific neuroprotection induced by sevoflurane preconditioning. Anesthesiology 121: 549-562. [Medline] [CrossRef]

25. Lu, X., Ma, L., Ruan, L., Kong, Y., Mou, H., Zhang, Z., Wang, Z., Wang, J.M., and Le, Y. 2010. Resveratrol differ- 
entially modulates inflammatory responses of microglia and astrocytes. J. Neuroinflammation 7: 46. [Medline] [CrossRef]

26. Ma, H., Yao, L., Pang, L., Li, X., and Yao, Q. 2016. Tetrandrine ameliorates sevoflurane-induced cognitive impairment via the suppression of inflammation and apoptosis in aged rats. Mol. Med. Rep. 13: 4814-4820. [Medline] [CrossRef]

27. Milad, M.R., Igoe, S.A., Lebron-Milad, K., and Novales, J.E. 2009. Estrous cycle phase and gonadal hormones influence conditioned fear extinction. Neuroscience 164: 887-895. [Medline] [CrossRef]

28. Puig, N.R., Ferrero, P., Bay, M.L., Hidalgo, G., Valenti, J., Amerio, N., and Elena, G. 2002. Effects of sevoflurane general anesthesia: immunological studies in mice. Int. Immunopharmacol. 2: 95-104. [Medline] [CrossRef]

29. Reutershan, J., Chang, D., Hayes, J.K., and Ley, K. 2006. Protective effects of isoflurane pretreatment in endotoxin-induced lung injury. Anesthesiology 104: 511-517. [Medline] [CrossRef]

30. Rudolph, J.L. and Marcantonio, E.R. 2011. Review articles: postoperative delirium: acute change with long-term implications. Anesth. Analg. 112: 1202-1211. [Medline] [CrossRef]

31. Salo, M. 1992. Effects of anaesthesia and surgery on the immune response. Acta Anaesthesiol. Scand. 36: 201-220. [Medline] [CrossRef]

32. Satomoto, M., Satoh, Y., Terui, K., Miyao, H., Takishima, K., Ito, M., and Imaki, J. 2009. Neonatal exposure to sevoflurane induces abnormal social behaviors and deficits in fear conditioning in mice. Anesthesiology 110: 628-637. [Medline]
[CrossRef]

33. Song, W.J., Son, M.Y., Lee, H.W., Seo, H., Kim, J.H., and Chung, S.H. 2015. Enhancement of BACE1 activity by p25/ Cdk5-mediated phosphorylation in Alzheimer's disease. PLoS One 10: e0136950. [Medline] [CrossRef]

34. Sun, Z., Satomoto, M., Adachi, Y.U., Kinoshita, H., and Makita, K. 2016. Inhibiting NADPH oxidase protects against long-term memory impairment induced by neonatal sevoflurane exposure in mice. Br. J. Anaesth. 117: 80-86. [Medline] [CrossRef]

35. Vasconcelos, A.R., Yshii, L.M., Viel, T.A., Buck, H.S., Mattson, M.P., Scavone, C., and Kawamoto, E.M. 2014. Intermittent fasting attenuates lipopolysaccharide-induced neuroinflammation and memory impairment. J. Neuroinflammation 11: 85. [Medline] [CrossRef]

36. Wang, H., Lu, S., Yu, Q., Liang, W., Gao, H., Li, P., Gan, Y., Chen, J., and Gao, Y. 2011. Sevoflurane preconditioning confers neuroprotection via anti-inflammatory effects. Front. Biosci. (Elite Ed.) 3: 604-615. [Medline]

37. Xu, Z., Dong, Y., Wang, H., Culley, D.J., Marcantonio, E.R., Crosby, G., Tanzi, R.E., Zhang, Y., and Xie, Z. 2014. Agedependent postoperative cognitive impairment and Alzheimer-related neuropathology in mice. Sci. Rep. 4: 3766. [Medline] [CrossRef]

38. Yang, Q., Dong, H., Deng, J., Wang, Q., Ye, R., Li, X., Hu, S., Dong, H., and Xiong, L. 2011. Sevoflurane preconditioning induces neuroprotection through reactive oxygen species-mediated up-regulation of antioxidant enzymes in rats. Anesth. Analg. 112: 931-937. [Medline] [CrossRef] 